\title{
O EXAME DE SUPLÊNCIA PARA QUALIFICAÇÃO PROFISSIONAL DE AUXILIARES DE ENFERMAGEM EM MINAS GERAIS
}

Mara José Moraes Antunes ${ }^{1}$

\begin{abstract}
RESUMO: Estudo analítico-descritivo da demanda e dos índices de aprovação do exame de suplência da Secretaria de Estado de Educaçăo de Minas Gerais para qualificação profissional de auxiliar de enfermagem e das características da clientela que se submete ao exame.
\end{abstract}

UNITERMOS: Exame de Suplência para Auxiliar de Enfermagem.

\section{1 - INTRODUÇÃO}

A busca de qualidade dos serviços de saúde torna fundamental a discussăo da qualificaçăo da força de trabalho empregada no setor.

Para tanto é importante considerar que $50 \%$ da força de trabalho dos serviços de saúde é composta de trabalhadores de enfermagem, dos quais cerca de $60 \%$ não tem qualificação específica para o setor, conhecidos com atendentes de enfermagem (Conselho Federal de Enfermagem, 1985).

Ao executar, majoritariamente, açőes de enfermagem, os atendentes de enfermagem contribuem para estabelecer o padrăo de qualidade dos serviços de saúde e especialmente de enfermagem.

Assim, a busca de qualidade na produção dos serviços de saúde exige primordialmente investimentos na formaçăo e qualificação deste contingente de trabalhadores sem o que qualquer discussão sobre exceléncia de serviços de saúde torna-se falaz.

Paralela à necessidade de profissionalizaçăo dos atendentes para a melhoria da qualidade da assistência à saúde encontra-se a obrigaçăo das instituiçőes de saúde, em cumprir a Lei $7.493 / 86$ que regula o exercício profissional da enfermagem no país, englobando em seus quadros de pessoal somente profissionais de enfermagem com registro nos Conselhos Regio- nais de Enfermagem, além do acima apontado, existe a aspiração de valorizaçăo social e profissional dos atendentes, que buscam a ascensăo funcional aos Planos de Cargos e Carreiras, criados no serviços públicos de saúde a partir da criaçăo do Sistema Único de Saúde.

As alternativas oficiais de mecanismos profissionalizantes para formaçăo dos atendentes em auxiliares de enfermagem são o ensino regular e o ensino supletivo. $O$ ensino regular se dá através de escolarizaçăo sistemática, com freqüência obrigatória, com cargas horárias fixas, e aferição de resultados no processo. $O$ ensino supletivo está destinado aos que não cursaram o ensino regular ou profissional e podem ser desenvolvidos em instituições especializadas ou no próprio ambiente de trabalho.

A alternativa de formaçăo via supletivo permite várias modalidades: aprendizagem, qualificação, suplência e suprimento. As modalidades aprendizagem e qualificaçăo exigem estudos sistemáticos e freqüência obrigatória aos cursos e avaliaçăo somativa e formativa no processo. As alternativas supléncia e suprimento permitem flexibilidade na freqüe̊ncia, duração, oferta e aferição dos resultados (GALVÃO, s.n.d).

A modalidade de alto teor de suplência permite que o candidato submeta-se anualmente a exames de aferiçăo de conhecimentos específi-

1. Enfermeira especialista em Saúde Pública, Mestranda em Enfermagem pela EEUFMG. Belo Horizonte, 1994. 
cos exigidos pelo sistema formal para a qualificaçăo pretendida, independente de freqüência a cursos.

Em Minas Gerais esta modalidade é conhecida popularmente como "provăo". Foi normaltizada pelo Conselho de Educaçăo de Minas Gerais, através da Resoluçăo 386 de 15.03.81, destinando-se a adultos maiores de 21 anos, desenvolvendo atividades específicas da habilitação pretendida há no mínimo dois anos e que tenham concluído o curso básico (oitava série do primeiro grau). Além do "provão", funcionam regularmente 54 escolas de técnicos e auxiliares de enfermagem distribuidas principalmente na regiăo centrosul do Estado.

Existem portanto, mecanismos para a formação dos atendentes em auxiliares de enfermagem, capazes de contribuir para o resgate de sua cidadania profissional e possibilitar a melhoria da qualidade da assistência de enfermagem prestada à populaçăo em nosso Estado.

No entanto, a qualificação dos atendenetes parece não ser prioridade para a maioria dos empregadores públicos e privados no estado de Minas Gerais, posto que não se observa, nos últimos anos, nenhum investimento de impacto que priorizasse a formação deste vasto contigente de trabalhadores já empregados na rede de saúde.

Assim, os atendentes de enfermagem, buscando adequar-se a Lei do Exercício Profissional de Enfermagem para garantir estabilidade e ascensão funcional parecem estar buscando, individualmente, na via supletiva-profissionalizante de alto teor, uma alternativa facilitadora para a sua titulação.

Buscando contribuir para a análise da situação acima descrita, o presente trabalho tem por objetivo conhecer a altemativa de formaçăo profissional dos auxiliares de enfermagem via exame de supléncia profissional de alto teor através do estudo e análise de:

- demanda e índice de aprovação nos ultimos anos;

- características da clientela.

\section{2 - DE ONDE VEM OS ATENDENTES E SUAS ALTERNATIVAS DE PROFISSIONALIZA- ÇÃO}

A história da assistência de enfermagem remonta aos primórdios da história da organizaçăo social da humanidade. Exercida inicialmente pelas mães de família, foi com o passar dos tempos sendo transferida, no mundo ocidental, para as măos de sacerdotes è leigos cristăos, conformando-se em atividade socialmente gratuita a cargo de mulheres caridosas e abnegadas, até o surgimento do protestantismo ao final da Idade Média (PAIXĀO, 1963). Neste período, a enfermagem religiosa foi expulsa dos hospitais, sendo substituída por pessoal civil não absorvido pelo trabalho industrial, que exerciam em extenuantes jornadas de trabalho e exígua remuneraçăo, as atividades de lavagens de roupa e limpeza do ambiente hospitalar (ALMEIDA, et alii, 1986).

No bojo do desenvolvimento do modelo industrial capitalista desenvolve-se o conhecimento da medicina. Os hospitais se transformam em local de cura e aperfeiçoamento da ciência médica. O SABER médico transforma-se em poder, passando a comandar e a direcionar o processo de trabalho na saúde.

Segundo ALMEIDA, et alii (1986), a enfermagem surge como profissão desenvolvendo conhecimentos e técnicas para cuidar dos pacientes, subordinada ao conhecimento médico. No seu desenvolvimento, o processo de trabalho da enfermagem incorpora a divisão técnica e social, institucionalizado por Florence Nightingale, na Inglaterra, no fim do século XIX. Assim cabia às Ladys Nurses, oriundas de famílias de extratos sociais elevados as atividades intelectuais, como ensino e supervisão. Às Nurses, provenientes da populaçăo pobre eram destinadas as tarefas de execução dos cuidados do paciente e ambiente (BARBOSA, 1991).

No Brasil, o trabalho da enfermagem estava sob a responsabilidade de congregaçőes religiosas, que coordenavam a assistência prestada por leigos contratados. A institucionalizaçăo formal da dicotomia entre o pensar e o fazer reproduzido na divisão técnica do trabalho na enfer- 
magem surge com a criaçăo das primeiras escolas de enfermagem, com a criação da "Escola Profissional de Enfermeiros e Enfermeiras", mais tarde "Alfredo Pinto" em 1980; da "Escola da Cruz Vervelha "em 1916 e da Escola de Enfermagem Dona Ana Néri" em 1926. (BARBOSA, 1991).

Aos poucos, os serviços de enfermagem saem das măos caritativas das religiosas e se institunaliza em duas categorias: as de "enfermeiras diplomadas" que cumpriam o papel destinado às Ladys Nurses de Florence Nightingale e as das "atendentes de enfermagem", incorporadas ao mercado de trabalho sem nehuma qualificação profissional formal, mas sob o controle das primeiras, exercido através da exigéncia dao cumprimento rígido das técnicas e princípios de enfermagem (ALMEIDA, et alii, 1986).

A Lei 775 de 1949 que dispunha sobre o ensino de enfermagem no país, legítima como categorias profissionais os "enfermeiros" com curso superior e os "auxiliares de enfermagem"com nível primário de escolaridade, năo fazendo referência ou regulamentando a formaçăo dos atendentes de enfermagem, sempre majoritários nos serviços de saúde.

Assim, em 1956, existiam no país 33 escolas para enfermeiros e 41 cursos de auxiliares de enfermagem. A força de trabalho da categoria era constituida de $\mathbf{4 2 . 9 3 1}$ trabalhadores, dividida em $11,3 \%$ de enfermeiros, $4,6 \%$ de auxiliares de enfermagem e de $84,1 \%$ de atendentes (BARBOSA, 1991).

A Lei de Direetrizes e Bases da Educaçăo Nacional, número 4.024 de 1961, cria as escolas técnicas de enfermagem destinadas aos que tivessem concluídos os estudos do primeiro ciclo de nível médio,mantendo os cursos de enfermagem como nível superior e os de auxiliares de enfermagem a nível ginasial. A criaçăo do curso técnico de enfermagem acompanha a criaçăo dos cursos técnicos no país, decorrentes das necessidades de incorporaçăo tecnológica surgidas com a expansão e modernização do parque industrial brasileiro.

A Lei 5.692/71 e diversas resoluçőes do Conselho Federal de Educaçăo - CFE estabeleceram alternativas para a formação do auxiliar de enfermagem. A Resoluçăo 07/77 (CFE) estabelece a habilitação de auxiliar de enfermagem a nivel de segundo grau. Porém a Resolução 08/ 77 permite, em carater transitório e emergencial, a formaçăo do auxiliar de enfermagem a nivel de primeiro grau. As habilitaçס̄es previstas nestas resoluçőes podem advir através de cursos de formação regular ou via supletiva. $O$ acesso à alternativa supletiva se dá através de cursos especiais ligados à instituições especificas ou por simples exames anuais ("provăo") para verificaçăo de conhecimentos, direcionados aos que já exercem atividades práticas de enfermagem.

Uma das alternativas de vanguarda, surgidas nos últimos tempos para a qualificaçăo dos trabalhadores de nivel elementar, empregado na rede de saúde sem qualificação profissional, inclusive dos atendentes é o Projeto Larga Escala. Desenvolvido por técnicos da OPAS e do Ministério da Saúde, o projeto propõe, a criação de Centros Formadores em unidades federadas. Estes Centros possibilitariam aos trabalhadores sem o ensino profissional e aos que não concluiram o curso fundamental (até a oitava série), o acesso aos cursos de qualificação específica, concomitantes, se necessário, aus cursos para a conclusão da escolarizaçăo fundamental. O projeto proposto para ser desenvolvido no próprio ambiente de trabalho do atendente, utiliza uma metodologia que integra a sua experiência acumulada e um conteúdo curricular voltado aos princípios da Reforma Sanitária em andamento no país (SANTOS, et al. 1989).

No entanto, o projeto Larga Escala não alcançou respaldo político intitucional capaz de transformá-lo em realidade na maioria dos estados brasileiros, especialmente em Minas Gerais.

A expansăo dos serviços de saúde hospitalares, a partir da década de 70 e a municipalização e expansão dos serviços ambulatoriais de saúde, surgida a partir da década de 80 , năo tem sido acompanhada de políticas de expansão de projetos ou alternativas para a qualificaçăo dos atendentes de enfermagem. Os atendentes continuam a serem incorporados à rede de serviços de saúde ou por falta de auxiliares 
de enfermagem no mercado de trabalho, especialmente no interior do estado por se constituirem de trabalhadores de măo de obra de baixo custo e de fácil substituição, apesar da fiscalização do Conselho Regional de Enfermagem.

Dados do trabalho realizado pelo Conselho Federal de Enfermagem em 1983, demonstram que os atendentes representavam $63,8 \%$ do pessoal que exercia atividades de enfermagem, ficando o restante distribuidos entre $8,5 \%$ de enfermeiros, $6,6 \%$ de técnicos e $21.1 \%$ de auxiliares de enfermagem (CONSELHO FEDERAL DE ENFERMAGEM,1985).

\subsection{Os Exames de Suplência para Auxiliares de Enfermagem e Caracterização de sua Clientela no Estado de Minas Gerais.}

A incorporação maciça dos atendentes de enfermagem aos serviços de saúde foi decorrente do modo de produção hegemónico nos país. Este modo de produção determinou a expansão dos serviços, especialmente os de saúde. A partir da década de 80 evidencia-se um agravamento do quadro social, económico e educacional no país. Uma das alternativas de emprego para aqueles que não conseguiram acesso à qualificação profissional era o mercado de trabalho hospitalar público ou privado, onde foram inseridos, especialmente como atendentes de enfermagem.

Estes trabalhadores desempenham, no processo coletivo do trabalho em saúde, ações de natureza complexa, sem preparo técnico e científico, contribuindo para a desqualificaçăo e a iatrogenia da assisténcia de enfermagem prestada à população (SANTOS, et alii.1989).

$A$ insuficiéncia de programas específicos públicos ou privados que invistam política e financeiramente na sua qualificaçăo remete o atendente a três alternativas: matricular-se em uma das escolas regulares de auxiliares de enfermagem, fora do seu horário de trabalho, com cursos de duração nunca menores que um ano, utilizar as alternativas de supléncia profissional ou nada fazer, premido pelas dificuldades financeiras e pelas barreiras educacionais. Em relação às escolas formais observa-se que os co- nhecimentos já adquiridos na prática da enfermagem năo privilegiam ou diferenciam o atendente dos demais matriculados procedentes da comunidade, sem nenhuma experiência. Ambos cumprem a mesma carga horária e o mesmo conteúdo curricular. Para este contingente, constituido basicamente de mulheres, mães de familia e com baixa renda mensal, torna-se uma tarefa sobre-humana compatibilizar a freqüência às escolas regulares com seus expedientes domésticos e de trabalho.

A alternativa suplência profissional apresenta-se entăo como opção viável para que os atendentes de enfermagem se qualifiquem em auxiliares de enfermagem.

O exame de supléncia para auxiliares de enfermagem ocorre anualmente em nosso estado. Os canditados são submetidos a 13(treze) provas escritas, correspondentes as disciplinas da grade curricular dos cursos regulares de auxiliares de enfermagem, ou seja: Enfermagem Neuro-Psiquiátrica, Noçőes de Administração Aplicadas à Enfermagem, Enfermagem Médica, Enfermagem em Saúde Pública, Introdução à Enfermagem, Enfermagem Cirúrgica, Higiene e Profilaxia, Estudos Regionais, Nutrição e Dietética, Anatomia e Fisiologia Humanas, Psicologia e Ética Profissional e Microbiologia e Parasitologia. As provas são elaboradas por enfermeiras consultoras convidadas pela Diretoria de Avaliação de Ensino da Secretaria de Estado da Educação, com orientação pedagógica de especialistas em ensino do setor e aplicadas aos candidatos, no mesmo período, utilizando-se a infra- estrutura das Delegacias Regionais de ensino da Secretaria do Estado da Educação no Estado.

Após obter aprovação em todos os 13(treze) exames teóricos obrigatórios, o candidato submete-se à prova prática anual, centralizada em Belo Horizonte. Para a realização de cada uma das provas é cobrada, do candidato, uma taxa de inscrição, utilizada para o financiamento das despesas administrativas das mesmas.

A Coordenação do Exame Supletivo do Estado de Minas Gerais, realizou em 1985, um estudo junto aos candidatos ao exame de suplência de qualificaçăo para auxiliares de enfer- 
magem, com o objetivo de conhecer o perfil desses candidatos. $O$ estudo foi realizado utilizando-se como instrumento um questionário aplicado a $166(24,3 \%)$ do total de 682 atendentes presentes nos exames de qualificação para auxiliares de enfermagem. $O$ estudo evidenciou que a maioria dos candidatos são do Estado de Minas Gerais, do sexo feminino e encontravamse na faixa etária entre 26 e 30 anos, sendo que, $43 \%$ possuiam o segundo grau completo. Segundo o relatório do referido estudo, a maioria dos atendentes declarou fazer o exame para conseguir melhoria profissional. Relatam ainda exercer, com maior freqüéncia no seu trabalho diário as seguintes atividades: aplicação de injeções e soluçăo endovenosa, controle e registro de sinais vitais, preparo de leitos e unidades, coleta de material para exames de laboratório, cuidados a doentes hospitalizados e em ambulatório,preparo de clientes para consulta médica, preparo de instrumentos cirúrgicos, orientaçăo a indivíduos e a grupos da comunidade sobre saúde e realização de eletrocardiogramas.

O estudo "Perfil do Atendente de Enfermagem no Estado do Paraná "realizado entre os 12.065 atendentes cadastrados naquele Estado em 1991, representando $65,0 \%$ dos trabaIhadores de enfermagem evidenciou que: $89.7 \%$ eram do sexo feminino e $30,5 \%$ tinham menos de 30 anos. Possuiam escolaridade mínima a nivel de primeiro grau $66 \%$ dos inscritos, dos quais $23,5 \%$ o segundo grau e $1,6 \%$ o curso superior. O restante, $34 \%$ não concluiu o ensino básico. Os serviços hospitalares absorviam $66 \%$ dos atendentes de enfermagem paranaenses; $25 \%$ trabalhavam na rede básica de saúde e $9 \%$ em outros serviços de saúde. Trabalhavam em atividades de enfermagem há menos de 5 anos $68,4 \%$ dos atendentes, podendo -se inferir que foram admitidos no trabalho durante ou após o ano de 1986, época da publicação da Lei do Exercício Profissional da Enfermagem que os proscreve como categoria autorizada para 0 exercício da enfermagem (BARBOSA, 1991).

Muitos dos achados no estudo realizado no Estado do Paraná são próximos dos encontrados pela Coordenação do exame Supletivo do Estado de Minas Gerais.

\section{METODOLOGIA}

Este estudo foi realizado por ocasião da aplicação da prova prática de supléncia para qualificação em auxiliares de enfermagem, realizado em Belo Horizonte no Hospital Felício Rocho em janeiro de 1994.

A populaçăo compreendeu 349 (trezentos e quarenta e nove) atendentes de enfermagem que estavam participando desta prova em um total de 887 (oitocentos e oitenta e sete).

O método de coleta de dados foi o de entrevista (questões fechadas).

Definiu-se como categorias de análise:

1- em relação ao exame de suplência: Número de atendentes que se canditaram à supléncia em auxiliares de enfermagem a partir do ano de criaçăo do exame e índices de comparecimento e aprovaçăo total e por disciplinas.

2- em relação à caracterizaçăo da clientela que utiliza a alternativa exame de supléncia: características ligadas à: sexo, faixa etária, origem, tempo e local de exercício na enfermagem, além de posse de autorização provisória para exercício de atividades de enfermagem, emitido pelo Conselho Regional de EnfermagemCOREN - MG.

Trabalhou-se com dados primários e secundários. Os primários foram coletados em 349 entrevistas fechadas entre os 887 atendentes candidatos à prova prática para qualificação via suplência, realizado no Hospital Felício Rocho de Belo Horizonte, em Janeiro de 1994. Os dados secundários foram coletados nos arquivos da Diretoria de Avaliação de Ensino da Superintendéncia de Desenvolvimento de Ensino da Secretaria de Estado de Educaçăo de Minas Gerais.

As informações foram analisadas à luz da bibliografia consultada, utilizando-se percentuais para proceder à análise e às comparações entre as categorias trabalhadas.

\section{RESULTADO E DISCUSSŌES}

O exame de suplência teve início no Estado de Minas Gerais em1978. Pelas informações 
contidas na Tabela 1 pode-se visualizar a evolução do número de candidatos desde a implantação do exame de supléncia até 1990. Observa-se no entanto, que não foram encontrados os dados referentes aos anos de 1980, 1983, 1987.

Tabela 1

Número de Atendentes de Enfermagem candidatos ao Exame de Suplência para Qualificaç̌o om Auxillares de Enfermagem. Minas Gorais. 19781980.

\begin{tabular}{|c|c|c|c|c|}
\hline Anos & reertio & Presentes & Aprovados & $\%$ \\
\hline 1978 & 480 & 435 & 256 & $58.9 \%$ \\
1979 & 786 & 671 & 231 & $34.4 \%$ \\
1980 & $\ldots$ & $\ldots$ & $\ldots$ & $\ldots$ \\
1981 & 889 & 886 & 198 & $22.3 \%$ \\
1982 & 788 & 780 & 172 & $22.1 \%$ \\
1983 & 876 & $\ldots$ & $\ldots$ & $\ldots$ \\
1984 & 722 & 681 & 249 & $36.6 \%$ \\
1985 & $\ldots 82$ & $\ldots$ & $\ldots$ \\
1986 & 609 & 641 & 161 & $25.11 \%$ \\
1987 & $\ldots$ & $\ldots$ & $\ldots$ & $\ldots$ \\
1988 & 702 & 614 & 376 & $61.2 \%$ \\
1989 & 1.266 & 1.198 & 384 & $32.1 \%$ \\
1990 & 2.306 & 2.200 & 301 & $13.7 \%$ \\
\hline
\end{tabular}

Fonte: Socrotaria do Estedo de Educaço - SDE-DAVEN-1994

\begin{tabular}{|c|c|c|c|c|c|}
\hline Deceptere & mecrition & meones & $\mathbf{x}$ & Anoredon & * \\
\hline Ent. Nouro Pelquisticos & 350 & 200 & 04.4 & 179 & 51.4 \\
\hline Nospese do Administ. em Enf. & 300 & 302 & 992 & 192 & 52.6 \\
\hline Entormegem Mudice & 375 & 317 & as & 222 & 70.0 \\
\hline Entormegem Sovido Público & 453 & 307 & 876 & 256 & 64.5 \\
\hline Introducked entermegem & 422 & 208 & 710 & 240 & 56.9 \\
\hline Entermegen Crivipice & 437 & 305 & 803 & 293 & 74.1 \\
\hline Higiene e Proflexde & 40 & 304 & 80.5 & 118 & 29.9 \\
\hline Entudos Rogionais & $\mathbf{m}$ & 306 & 87.3 & 322 & 83.4 \\
\hline 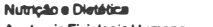 & 306 & 339 & 67.8 & 197 & 58.1 \\
\hline Anstomis Fisiologis Humana & 305 & $3: 2$ & $\infty 0$ & 28 & 68.7 \\
\hline 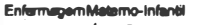 & 387 & 331 & 055 & 262 & 79.1 \\
\hline Pacologon e Évea Proflasional & 433 & 302 & 68.2 & 206 & 68.4 \\
\hline 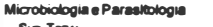 & 470 & 413 & 87.8 & 266 & 644 \\
\hline SUETOTN & 5.358 & 4.650 & $\$ 8.7$ & 3.071 & 88.0 \\
\hline Prova Presca & - & - & - & - & $=$ \\
\hline TOTN & 5.358 & 4.654 & 867 & 3.071 & 68.0 \\
\hline
\end{tabular}

ciplinas foi de $68 \%$. A disciplina com menor indice de aprovação foi Higiene e Profilaxia $(29,9 \%)$ e Estudos Regionais, com $83.4 \%$ a de maior aprovação.

Em 1991 (Tabela 3) a média de comparecimento aos exames teóricos subiu em relação a 1985 , atingindo o indice de $91,4 \%$. Os menores indices de comparecimento ocorreram nas dis-

Verifica-se ainda que a procu-

Tabola 3

Atondentes inscritos e aprovados no exame de supléncis

para quallificactlo em Auxillar do Enformagom - Minas Gorais - 1991 ra ao exame de supléncia cresceu durante todo o período, especialmente nos anos 1989 e 1990, quando o número de inscritos representou, respectivamente um aumento de $264 \%$ e de $480 \%$ em relação ao ano de 1978 , tendência que sugere o exame como alternativa importante de qualificação profissional dos atendentes de Minas Gerais. Ressalte-se que os pelounce

\begin{tabular}{|c|c|c|c|c|c|}
\hline Desclollines & inectioses & Presentese & \% & Aprovedos & $x$ \\
\hline Enf. Neuro Psiquidtrice & 1.085 & 1.081 & 99.6 & 987 & 91.3 \\
\hline Nogoes de Administ. em Enf. & 809 & 825 & 80.8 & 807 & 88.8 \\
\hline Enformegerm Modica & 231 & 841 & $\mathbf{8 0 . 3}$ & 736 & 79.0 \\
\hline Enformagem Saúde Pública & 1.445 & 770 & 53.3 & 675 & 46.7 \\
\hline Inooducto d Enformegem & 845 & 762 & $\infty 0.2$ & 689 & 81.5 \\
\hline Enformegern Cirurgica & 1.187 & 1.093 & $\mathbf{8 2 . 0}$ & 747 & 62.9 \\
\hline Higiene e Profilaxia & 870 & 795 & 91.4 & 601 & 79.4 \\
\hline Estudos Regionais & 1.001 & 835 & 93.4 & 855 & 85.4 \\
\hline Nutriçeo Dietetica & 1.657 & 850 & 51.3 & 807 & 48.7 \\
\hline Anatomia Fisiologia Humana & 1.101 & 1.012 & 81.8 & 963 & 89.3 \\
\hline Enformagem Materno-Infantil & 1.481 & 769 & 51.8 & 712 & 92.6 \\
\hline Psicologia \& Etica Profissional & 233 & 858 & 92.0 & 702 & 81.9 \\
\hline Microbiologia o Parasitologia & 94 & 861 & 91.2 & 439 & 51.0 \\
\hline SUB-TOTN & 12.525 & 11.452 & 91.4 & 9.831 & 85.8 \\
\hline Prova Pratica & 1.208 & 576 & 47.7 & 508 & 98.2 \\
\hline TOTN & 13.733 & 12.028 & 87.6 & 10.397 & 86.4 \\
\hline
\end{tabular}
índices de aprovação variaram ano a ano, apresentando o maior índice em 1988 (61.2\%) e o menor em 1990(13.7\%). A interpretação destes índices exige uma maior aprofundamento do estudo em pauta. No entanto pode - se inferir que o aumento na procura da titulação via suplência, tem relação com o movimento da Reforma Sanitária em implantação no país e com a fiscalização do exercício profrissional pelo Conselho Regional de Enfermagem a partir da promulgação da Lei 7498/ 86.

Em 1985 (Tabela 2), a média de comparecimento dos inscritos aos exames teóricos foi de $86,7 \%$ e a média de aprovação no total das dis-

ciplinas saúde pública(53,3\%) e Nutrição e Dietética( $51,3 \%)$, que apresentaram também os mais baixos índices de aprovação: $46,7 \%$ e $48,7 \%$ respectivamente. A média geral de aprovação no total da disciplinas foi de $85,8 \%$, maior também que a de 1985. É importante destacar na Tabela 3 o reduzido índice de comparecimento à prova prática $(47,7 \%)$, especialmente se comparados à média de comparecimentos às provas teóricas. Vale lembrar que as provas teóricas são realizadas nas diversas regionais de ensino, cobrindo todas as regiőes do estado de Minas Gerais, enquanto que a prova prática é centralizada em Belo Horizonte. Na nossa ex- 
periência pessoal como examinadora da prova prática ouvimos depoimentos de candidatos que viajaram mais de $600 \mathrm{Km}$, para o exame. Os técnicos da Secretaria de Estado de Educação responsáveis pela coordenaçăo do exame apontam como causa do alto índice de abstenção na prova prática, a carência de recursos financeiros dos candidatos para o deslocamento à capital.

dos candidatos a partir de sua experiência profissional conforme sua área de atuaçăo, ou seja: na área hospitalar ou de saúde pública.

Os dados da Tabela 5 confirmam a predominância feminina na composiçăo dos atendentes candidatos, comum às diversas categorias da enfermagem. Observa-se que dos submetidos ao exame de suplência $87 \%$ eram do sexo feminino.

Quanto à idade dos candidatos os dados da Tabela 6 demonstram que $40,2 \%$ dos atendentes tinham idade entre 21 a 30 anos. Acrescidos o maior índice encontrado na tabulação dos dados, correspondente aos $30,5 \%$ da faixa etária entre 31 a 35 anos, evidenciase que $70,7 \%$ dos atendentes tinham, à época do levantamento, menos que 35 anos de idade. Este dado indica a manutençăo nos ultimos anos da inserção de trabalhadores de enfermagem sem qualificação profissional específica no

Os dados da Tabela 4 demonstram que em 1993 ocorreu o crescimento do índice médio de comparecimento aos exames teóricos, que atingiu $95,0 \%$. A média de aprovaçăo nas provas teóricas foi de $75,4 \%$, menor que 0 atingido em 1991(85,8\%). Contribuiram para esta diminuição os índices de reprovação nas disciplinas Introduçăo à Enfermagem (47,4\%) e Anatomia e Fisiologia Humanas(69,8\%).

Manteve-se em 1993 o alto índice de abstenção na prova prática, realizada em janeiro de 1994, em Belo Horizonte. Dos que compareceram, $98,6 \%$ foram aprovados. O crescimento do índice de aprovação nas provas práticas é apontado como conseqüéncia da mudança de orientação técnico-pedagógica ocorrida na aplicaçăo da prova, a partir de 1991. As mudanças foram dirigidas para avaliar o desempenho funcional mercado de trabalho em saúde. Pode-se arguir da insuficiéncia ou ineficácia do sistema formador especifico de auxiliares de enfermagem, assim como das políticas de recursos humanos dos serviços de saúde frente a necessidade da qualidade da assiste̊ncia.

Tabola 6

Idade dos Atendentes de Enfermagem submetidos ao Exame de Suplência para Auxiliar de Enformagem - Minas Gorais - 1994

\begin{tabular}{|l|c|c|}
\hline \multicolumn{1}{|c|}{ Faixa Ethria } & Númoro & $\%$ \\
\hline 21 a 25 anos & 44 & 11.2 \\
26 a 30 anos & 114 & 29.0 \\
31 a 35 anos & 120 & 30.5 \\
36 a 40 anos & 72 & 18.0 \\
41 a 45 anos & 26 & 7.0 \\
46 a 50 anos & 12 & 3.0 \\
51 a 60 anos & 02 & 0.5 \\
61 a 65 anos & 01 & 0.3 \\
Neoinformeram & 02 & 0.5 \\
TotAl & 394 & 100.0 \\
\hline
\end{tabular}

Tabola 5

Sexo doe Atendentos

no Examo do Suplôncia para qualificaçăo

om Auxiliar de Enformagom - Minas Gorais - 1994

\begin{tabular}{|l|c|c|}
\hline \multicolumn{1}{|c|}{ Sexo } & Númoro & $\%$ \\
\hline Ferninino & 342 & 87 \\
Masculino & 52 & 13 \\
TotAL & 394 & 100 \\
\hline
\end{tabular}

Ao relacionar o ano de início do trabalho em enfermagem dos atendentes candidatos à qualificação em auxiliares de enfermagem, os dados da Tabela 7 mostram que continuam entrando no mercado de trabalho em saúde, trabalhadores sem qualificaçăo específica para o setor. Verifica- 
se que somente $31,5 \%$ dos candidatos tiveram seu primeiro emprego na enfermagem antes da vigéncia da Lei do Exercicio Profissional de Enfermagem, promulgada em 1986. Portanto, $68,5 \%$ foram admitidos a partir desta data, evidenciando o descumprimento desta legislaçăo pelos órgãos empregadores.

Tabola 7

Ano de inicio de exercicio na Enformagem dos Atendentes submetidos ao Exame de Suplôncia para Qualificaçăo em Auxiliar de Enfermagem - Minas Gerals - 1993

\begin{tabular}{|c|c|c|c|}
\hline Ano & Númoro & \% & \% Acumulado \\
\hline 1970 & 1 & 0.3 & 0.3 \\
1971 & 2 & 0.5 & 0.8 \\
1972 & 1 & 0.3 & 1.1 \\
1973 & 3 & 0.8 & 1.9 \\
1974 & 1 & 0.3 & 2.2 \\
1975 & 4 & 1.0 & 3.2 \\
1976 & 9 & 2.3 & 5.5 \\
1977 & 10 & 2.5 & 8.0 \\
1978 & 7 & 1.8 & 9.8 \\
1979 & 4 & 1.0 & 10.8 \\
1980 & 9 & 2.3 & 13.1 \\
1981 & 17 & 4.3 & 17.4 \\
1982 & 4 & 1.0 & 18.4 \\
1983 & 10 & 2.5 & 20.9 \\
1984 & 12 & 3.0 & 23.9 \\
1985 & 31 & 7.9 & 31.8 \\
1986 & 57 & 14.5 & 46.3 \\
1987 & 32 & 8.1 & 54.4 \\
1988 & 50 & 12.7 & 67.1 \\
1989 & 51 & 13.0 & 80.1 \\
1990 & 43 & 10.9 & 91.0 \\
1991 & 36 & 9.0 & 100.0 \\
TOTAL & 394 & 100.0 & 100.0 \\
\hline
\end{tabular}

A rede hospitalar continua a configurar-se como o maior empregador de atendentes de enfermagem, absorvendo $63 \%$ dos trabalhadores, conforme evidenciado na Tabela 8.

Tabola 8

Local de exerciclo dos atendontes de enfermagem que fizeram a prova pratica para qualificaço profissional om Auxiliar de Enformagem - Minas Gerais - 1994

\begin{tabular}{|l|r|r|}
\hline \multicolumn{1}{|c|}{ Origem } & Númoro & \% \\
\hline Unidades Hospitalares & 249 & 63 \\
Unidades Ambulatoriais & 111 & 28 \\
EnfermagemdoTrabalho & 7 & 2 \\
Outros & 4 & 1 \\
Nåinformaram & 23 & 6 \\
TOTAL & 394 & 100 \\
\hline
\end{tabular}

Os dados da Tabela 9, evidenciam que $78 \%$ dos atendentes năo possuiam autorizaçăo pré- via do Conselho Regional de Enfermagem de Minas Gerais para exercício da enfermagem, constituindo-se portanto de contingente marginal e independente de controle e fiscalização profissional.

Tabola 9

Atendentes com autorizaçె̄o provisória para exercicio da enfermagem do Conselho Regional de Enfermagem candidatos ao exame de suplência para qualificação om Auxiliar de Enfermagem - Minas Gerais - 1993

\begin{tabular}{|l|c|c|}
\hline \multicolumn{1}{|c|}{ AtendentosAutorizades } & Número & $\boldsymbol{\%}$ \\
\hline SIM & 24 & 21 \\
NÅO & 88 & 78 \\
NÅORESPONDERAM & 1 & 1 \\
TOTAL & 113 & 100 \\
\hline
\end{tabular}

Das informaçőes obtidas, agrupadas no quadro 9, evidencia-se que $78 \%$ não possuiam autorizaçăo do COREN-MG para trabalhar na enfermagem, constituindo portanto contingente marginal e independente de controle e fiscalização profissional.

Tabela 10

Origem dos atendentes de enfermagem candidatos ao exame de suplência para qualificaç̉o om Auxiliares do Enfermagem - Minas Gerais - 1993

\begin{tabular}{|l|c|c|}
\hline \multicolumn{1}{|c|}{ Atondentes Autorizadas } & Númoro & \multicolumn{1}{c|}{$\%$} \\
\hline Capital & 95 & 10.9 \\
Interior & 766 & 87.6 \\
NáoInformaram & 14 & 1.5 \\
TOTAL & 875 & 100.0 \\
\hline
\end{tabular}

Os dados da Tabela 10 demonstram que $87.6 \%$ dos atendentes candidatos à qualificação em auxiliares de enfermagem provem do interior do Estado. Este dado permite inferir a importância social do exame como única alternativa de qualificação para que os atendentes que residem em cidades onde não existem escolas de auxiliares de enfermagem, especialmente nas regiőes norte e nordeste do Estado.

\section{CONCLUSÃO}

Após análise dos dados coletados, concluise que a alternativa qualificaçăo profissional via suplência de alto teor tem-se configurado como crescente opção para as atendentes de enfermagem empregados na rede de serviços de 
saúde, especialmente para os do interior do estado de Minas Gerais.

A realização da prova prática, centralizada em Belo Horizonte tem sido fator dificultador para o comparecimento ao exame dos candidatos do interior do Estado, provavelmente devido à insuficiencia de recursos financeiros dos candidatos para o necessário deslocamento e sua manutenção na capital.

As modificações dos critérios de avaliação de desempenho funcional utilizados na prova prática implantados pelos coordenadores técnico-pedagógicos responsáveis pela coordenação do exame, a partir de 1991, contribuiram para o aumento do número de aprovados pelo fato de arguir os candidatos na sua área de atuação profissional: hospitalar ou ambulatorial.

A insuficiência numérica e a concentração das escolas de auxiliares de enfermagem na região centro-sul do Estado parece estar contribuindo para a manutenção do ingresso de pessoal sem qualificação específica na prestação de serviços de enfermagem. Outro fator que pode estar contribuindo para esta situação é a contratação desse pessoal pelos serviços de saúde, desafiando à legislação do exercício da enfermagem vigente.

Os hospitais continuam sendo os maiores empregadores de atendentes de enfermagem. No entanto, o crescimento dos serviços municipais de saúde decorrentes da implementação do SUS no Estado aponta para a ampliação do mercado de trabalho de enfermagem na área de saúde pública, indicando necessidade de aprofundamento deste estudo.
As atendentes de enfermagem são majoritáriamente mulheres jovens; $68,3 \%$ inseriram-se no mercado de trabalho após a vigéncia da Lei do Exercício Profissional de Enfermagem em 1986.

Apesar do Conselho Regional de Enfermagem de Minas Gerais fiscalizar o exercício profissional da categoria, este estudo levantou que $78 \%$ dos atendentes analisados, não possuiam autorização do Conselho Regional de Enfermagem para o exercício de suas atividades. Constituem, portanto, um contingente marginal de trabalhadores exercendo atividades de enfermagem independente do orgão regulamentador e fiscalizador da profissão.

Acreditamos que o investimento na qualificaçãodos atendentes de enfermagem é prioridade máxima para elevação dos padrões de qualidade da assisténcia de enfermagem prestados à população mineira. Para tanto se faz necessário acelerar os projetos de pesquisa sobre os atendentes de enfermagem em andamento no Estado e projetos de qualificação descentralizada que considerem a realidade social deste contigente, a exemplo do Projeto Larga Escala.

Assim aos atendentes empregados na rede de saúde do Estado de Minas Gerais seria possibilitado o resgaste da cidadania profissional e social. Ao mesmo tempo a população mineira receberia assisténcia de enfermagem com um padrão de qualidade condizente com suas necessidades e direitos de cidadania.

\begin{abstract}
A descriptive analytical study for the demand and the suplementary exams passing rates State Education Secretary of Minas Gerais for the professional qualification of auxiliar nurses and the clientele characteristics who take the exam.
\end{abstract}

KEYWORDS: Suplementary Exam for Auxiliar Nurses 


\section{REFERÊNCIAS BIBLIOGRÁFICAS}

ALMEIDA, Maria Cecilia Puntel de, \& ROCHA, J.S.Y. O saber de enfermagem e sua dimensão prática. São Paulo: Cortez, 1986.

BARBOSA, Jurandy Kern. A profissionalização do atendente: um pressuposto para melhorar a qualidade da assistência de enfermagem. Curitiba, Dissertação de Mestrado em Educação - Universidade Federal do Paraná, 1991.

BRASIL, Conselho Federal de Enfermagem. O exercício da enfermagem nas instituições de saú- de no Brasil: 1982-1983, Força de trabalho em enfermagem. Rio de Janeiro: 1985 V.1.

GALVÃO Ena de Araújo. Formação de pessoal de primeiro e segundo grau -base legal [s.l.], Curso de Atualização em Desenvolvimento de Recursos Humanos de Saúde -Unidade III, mimeo, (s.n.d.)

PAIXĀO, Waleska. Páginas da história de enfermagem. 3 ed. Rio de Janeiro: Bruno Buccini, 1963.

SANTOS, Isabel \& SOUZA, A.M de. Formação de pessoal de nivel médio pelas instituições de saúde: projeto larga escala, uma experiência em construção.Rev.Saúde em Debate, Londrina, mar., p. 61-64,1989. 